\title{
Expedient placement of two fluorescent dyes for investigating dynamic DNA protein interactions in real time
}

\author{
Sanford H. Leuba ${ }^{1 *}$, Syam P. Anand ${ }^{2}$, Joel M. Harp ${ }^{3} \&$ Saleem A. Khan ${ }^{2}$ \\ ${ }^{1}$ Departments of Cell Biology and Physiology and Bioengineering, University of Pittsburgh School of Medicine \\ and Swanson School of Engineering, Petersen Institute of NanoScience and Engineering and University \\ of Pittsburgh Cancer Institute, Pittsburgh, PA 15213, USA; Tel: +1-412-623-7788; Fax: +1-412-623-4840; \\ E-mail: leuba@pitt.edu; ${ }^{2}$ Department of Microbiology and Molecular Genetics, University of Pittsburgh School \\ of Medicine, University of Pittsburgh Cancer Institute, Pittsburgh, PA 15261, USA; ${ }^{3}$ Department of Biochemistry, \\ Vanderbilt University School of Medicine, Nashville, TN 37232, USA \\ * Correspondence
}

Key words: fluorescence resonance energy transfer, FRET, nucleosome, PcrA, RecA

\begin{abstract}
Many questions in molecular and cellular biology can be reduced to questions about 'who talks to whom, when and how frequently'. Here, we review approaches we have used with single-pair fluorescence resonance energy transfer (spFRET) to follow the motions between two well-placed fluorescent probes to ask similar questions. We describe two systems. We have used a nucleosomal system in which the naked DNA molecule has the acceptor and donor dyes too far apart for FRET to occur whereas the dyes are close enough in the reconstituted nucleosome for FRET. As these individual nucleosomes were tethered on a surface, we could follow dynamics in the repositioning of these two dyes, inferring that nucleosomes stochastically and reversibly open and close. These results imply that most of the DNA on the nucleosome can be sporadically accessible to regulatory proteins and proteins that track the DNA double helix. In the case of following the binding of recombination protein RecA to double-stranded DNA (dsDNA) and the RecA filament displacement by DNA helicase motor PcrA, the dsDNA template is prepared with the two dyes close enough to each other to generate high FRET. Binding of the RecA molecules to form a filament lengthens the dsDNA molecule 1.5-fold and reduces the FRET accordingly. Once added, DNA motor protein helicase PcrA can displace the RecA filament with concomitant return of the DNA molecule to its original B-form and high FRET state. Thus, appropriately placed fluorescent dyes can be used to monitor conformational changes occurring in DNA and or proteins and provide increased sensitivity for investigating dynamic DNA-protein interactions in real time.
\end{abstract}

\section{Introduction}

The combination of physics and biology has led to single-molecule approaches in which one macromolecule is studied (Science 1999, JBC 1999, Leuba \& Zlatanova 2001, Rigler et al. 2002, Zander et al. 2002). Asynchronous processes such as transcription can be followed one-molecule-at-a-time (Zlatanova et al. 2006). Single-molecule approaches including electron microscopy and atomic force microscopy and magnetic and optical tweezers have already clarified chromatin structure and dynamics (Leuba \& Zlatanova 2002, Zlatanova \& Leuba 2002, 2003a,b, 2004b, Zlatanova 2003, Leuba et al. 2004, Claudet \& Bednar 2006, van Holde \& Zlatanova 2006, Zlatanova \& van Holde 2006), such as the 
three-dimensional arrangement of nucleosomes in a chromatin fiber, the piconewton forces needed to unravel individual nucleosomes and the stretching forces applied to DNA needed to prevent nucleosome assembly.

Movements in molecular complexes can be mapped to three-dimensional distance changes between any two points over time. The change in the distance between two attached fluorescent dyes serves as an indicator of larger-scale conformational changes. Expedient placement of two fluorescent dyes, a donor and acceptor dye pair, facilitates measurement of dynamic DNA and or protein conformations through single-pair fluorescence resonance energy transfer (spFRET). spFRET is FRET from one donor dye to one acceptor dye molecule (recently reviewed in Zheng et al. 2007, Deniz et al. 2008). The following formula indicates the distance relationship of FRET: $E_{\mathrm{FRET}}=1 /\left(1+\left(R / R_{0}\right)^{6}\right)($ Clegg 1992$)$, where $E_{\mathrm{FRET}}$ is the efficiency of FRET (Förster 1959), $R$ is the radius between the acceptor and donor dye and $R_{0}$ is the distance at which 50\% FRET occurs between the two dyes (Förster 1959). Reversible conformational transitions that bring the two covalently attached dyes close together and then farther apart on the same molecule will result in anti-correlated intensities of the two independent dyes, confirming that they are on the same molecule. The transfer of energy is affected also by the orientation of the two dyes. Most spFRET studies rely on the relative changes in FRET rather than absolute distance changes (Ha 2001). spFRET occurs within $\sim 2$ to $\sim 8 \mathrm{~nm}$ in a commonly used dye pair, cyanine dyes Cy3 and Cy5 (Mujumdar et al. 1993). The $R_{0}$ for this dye pair is $6 \mathrm{~nm}$ (Tan et al. 2003). With the quality of fluorescent dye pairs presently available (Mujumdar et al. 1993) and recent developments in spFRET (Weiss 1999, Selvin 2000, Ha 2001, Zheng et al. 2007, Deniz et al. 2008), it should be possible to follow these nanometer motions in the millisecond timescale range.

In this review, we will describe two approaches based on site-specific fluorescently labeled dsDNA templates that we have used to follow nucleosome opening, recombination protein assembly and disassembly, and DNA helicase translocation. The purpose of this review is not to give a comprehensive coverage of the progress made in these two model systems, but to give the reader an idea of how different dye placements can be used to follow dynamics in DNA-protein interactions.

\section{Fluorescent labeling of proteins or DNA molecules}

In proteins deficient in cysteine, an introduced cysteine can be used as a handle for the maleimide of the fluorescent dye. Nucleic acid suppliers can prepare oligonucleotides with a fluorescent dye at the $5^{\prime}$ end, the $3^{\prime}$ end, and/or some dyes internally such as tetramethylrhodamine (e.g. www.IDTDNA.com). Alternatively, nucleic acid companies can produce oligonucleotides with internal amino linkers, which can be labeled chemically with the $N$-hydroxysuccinimide ester of the fluorescent dye (e.g., Zheng et al. 2005). Another method to label one strand of dsDNA is to use the other strand as a template containing two or three out of four nucleotides. Then, using Klenow polymerase, the other strand is polymerized using one or two nucleotides that are fluorescently labeled internally, e.g., (Anand et al. 2007). Highly fluorescently labeled commercial oligonucleotides can be expensive, whereas Klenow polymerase can perform the labeling specifically at a much lower cost.

\section{Nucleosomes}

The nucleosome is the fundamental DNA-protein portion of a chromosome. Eukaryotic DNA is packaged in chromatin, which poses a problem to DNA transactions (transcription, replication, repair, recombination) that must access the underlying DNA template (van Holde 1988, Wolffe 1998, Zlatanova $\&$ Leuba 2004a). Some 150 bp of DNA are wrapped almost twice around an octamer of core histones $\mathrm{H} 2 \mathrm{~A}, \mathrm{H} 2 \mathrm{~B}, \mathrm{H} 3$ and $\mathrm{H} 4$ to form the nucleosome. A fifth histone, linker histone $\mathrm{H} 1$, binds to the DNA entering and exiting nucleosomes and to the ensuing linker DNA connecting adjacent nucleosomes.

The positions of $70 \%$ of the core histone amino acids have been mapped with exquisite detail in the crystal structures of the histone octamer (Arents et al. 1991) and the 146 bp or 147 bp nucleosome (Luger et al. 1997, Harp et al. 2000, Davey et al. 2002). The remaining $\sim 30 \%$ of the core histone amino acids are in the histone tail termini where most of the posttranslational modifications such as acetylation, methylation and phosphorylation occur. Histone posttranslational modifications as well as modifications to the DNA structure itself (e.g. DNA methylation) are thought to assist with regulation of nucleosomal and chromatin fiber stability. Additionally, the exchange between the 
canonical histones and their evolutionarily conserved variants are thought to assist with regulation. Finally, ATP-dependent nucleosome remodeling proteins and complexes contribute to regulation (for a review see Travers \& Owen-Hughes 2004). It is not well understood mechanistically how these modifications may assist with dynamic regulation of access to the underlying DNA templates for processes such as transcription, replication, repair and recombination.

\section{Regulation of access to the underlying DNA templates}

Dynamic changes in nucleosomes regulate genetic responses in the cell. Current assays used to study spontaneous or factor-induced dynamic changes in chromatin structure rely on population-averaged measurements that may not be sensitive enough to detect fast reversible changes. Moreover, the disparate biological events that can occur in one molecule are lost in the average of the population of many molecules.

\section{Nucleosomes stochastically open and close}

In the case of the nucleosome, a dsDNA template is prepared with the two dyes too far away for FRET to occur as naked DNA (Figure 1A), but when the DNA is folded around the histone octamer to form a nucleosome, the two dyes come into close enough proximity for FRET (Figure 1B) (Tomschik et al. 2005). Note that the sites for the two dyes are on the opposite side of the nucleosome from the pseudodyad of the nucleosomal DNA positioning sequence. In our experiments, in order for FRET to decrease from the high-FRET canonical nucleosomal state, the DNA has to unwrap from the histone octamer core by at least 30-40 bp before FRET can even begin to decrease. We have estimated that the methyl carbons of the pyrimidines upon which the Cy3 and Cy5 dyes are mounted are $2.8 \mathrm{~nm}$ apart in the formed nucleosome.

In our application, we use an evanescent-field fluorescent microscope (e.g., Zheng et al. 2005), otherwise known as total internal reflection fluorescence microscope (Axelrod 1981), with a wide field illumination from a laser. The evanescent field generated by the laser excites donor fluorescent dyes on DNA molecules tethered to a surface. The fluorescence image of these excited molecules is split into two equal images that are filtered separately with either a green (donor dye signal) or a red filter (acceptor dye signal) and the resulting images are collected side by side, left and right, simultaneously with a video camera that has the sensitivity to detect the intensity of single fluorescent dyes. This approach is analogous to what astronomers did over 40 years ago to measure red shifts in stars (Baum 1962). The actual data from imaging of single fluorescent dye molecules attached to a surface, which appear as scattered white spots of intensity against a black background, does in fact resemble looking at a constellation of stars at night. From the constellation of intensities of the two images, an anticorrelation of intensities of the same spot in the left and right images over time indicates the dyes are on the same DNA molecule.

In the case of imaging a population of individual naked nucleosomal positioning DNA molecules, the donor and acceptor dyes are too far apart for FRET to occur and the intensity is concentrated in the green channel (Figure 2A). The apparent efficiency of FRET $\left(E_{\text {app }}\right)$ is the fraction of the total amount of absorbed energy that is transferred from the donor dye to the acceptor dye and can be roughly determined from the data as the ratio of the acceptor intensity divided by the sum of the intensities of the acceptor and donor dyes (Clegg 1992, 1995). Additionally, one has to take into account spectral crosstalk of the donor signal into the acceptor channel. In the case of naked DNA molecules, the average $E_{\text {app }}$ after correction for spectral crosstalk is 0.13 (Figure 2A histogram). Once the DNA molecules are reconstituted into nucleosomes, the two dyes are in close proximity for energy transfer to occur; a strong register of intensities is observed in the right image (Figure $2 \mathrm{~B}$ ) and the histogram is shifted to $0.87 E_{\text {app }}$ units. Rinsing the reconstituted nucleosome slide with $2 \mathrm{M} \mathrm{NaCl}$ removes all of the proteins, and the naked DNA molecules left behind regain the low-FRET signal of $0.11 E_{\text {app }}$ units (Figure 2C).

There are several methods for reconstituting nucleosomes, including (i) salt dialysis (Tatchell \& Van Holde 1977) and salt jump (Zivanovic et al. 1990) and (ii) reconstitution using histone chaperones such as nucleosome assembly protein Nap1 (Ishimi et al. 1983). Nucleosomes first reconstituted by salt dialysis or salt jump beginning from a high salt and dialyzing or diluting to a low salt are then attached to the quartz surface by biotin-streptavidin linkages. On the other hand, chaperone-assembled 


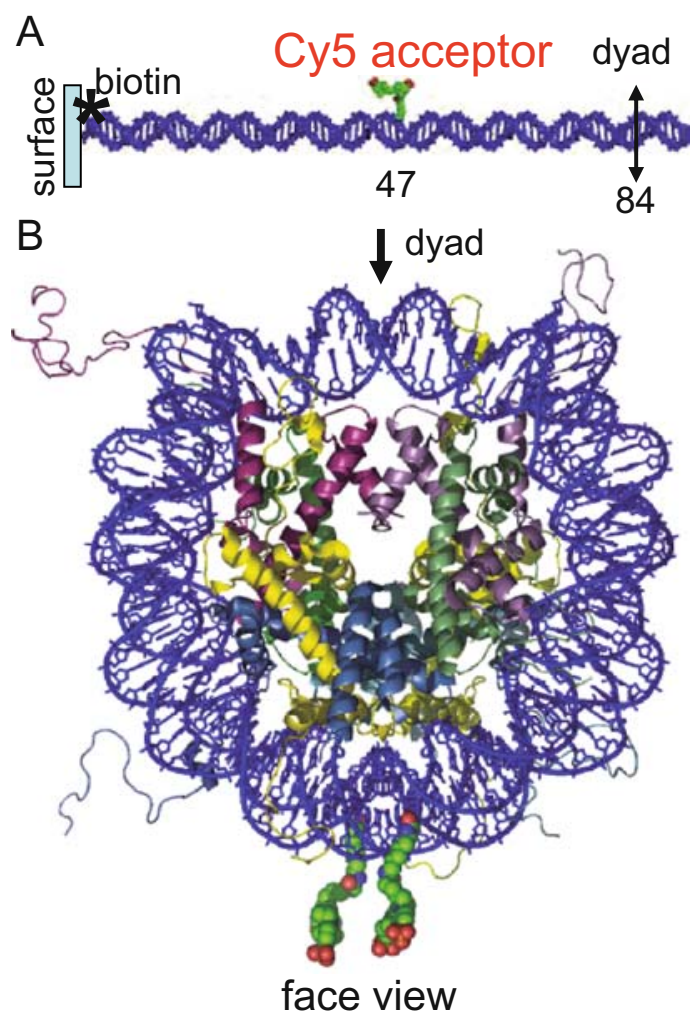

Figure 1. Fluorophore positions on naked DNA and nucleosomes (Tomschik et al. 2005). (A) Model of a 164 bp dsDNA molecule with covalently bound cyanine dyes (Mujumdar et al. 1993). Donor Cy3 dye is at position 122 and acceptor Cy5 dye is at position 47. The dyad of the nucleosome positioning sequence is at position 84. (B) Model face and side views of a nucleosome (1kx5) (Davey et al. 2002) with the attached cyanine dye pair. Attachment of dyes was performed using Xfit (McRee 1993) and models displayed in PyMOL (DeLano 2002).

nucleosomes can be assembled in situ on the quartz glass. We have used both methods.

The images in Figure 2 are snapshots from a video. Hence, we can follow the intensity of the two dyes attached to one DNA molecule over time to view a time trajectory (Figure 3). Here, the red trace is the intensity of the acceptor dye and the green trace is the intensity of the donor dye. The anti-correlated intensities ensure that we are following the stochastic behavior of a single nucleosome. The two dyes reversibly revert between high and low FRET states before the acceptor dye photobleaches. The photobleached state is significantly lower than the low state, indicating that the low state does not represent photoblinking events of the acceptor dye molecule. Schematics of the two states, a closed canonical state and open states either with symmetrical or asymmetrical DNA opening, are indicated either below or above the time trajectory, respectively, correlating with the observed FRET signals.
Based on the specific placement of the two dyes (deep within the nucleosomal particle), we observed long-range conformational fluctuations, with almost half of the nucleosomal DNA being unwrapped within $100 \mathrm{~ms}$ (Tomschik et al. 2005). This interpretation was supported by fiber stretching experiments performed with optical tweezers (Brower-Toland et al. 2002), and by theory (Marky \& Manning 1991, 1995). These results implied that most of the DNA on the nucleosome can be sporadically accessible to regulatory proteins and proteins that track the DNA double helix. We suggest that histone modifications or variant replacement and/or ATP-dependent nucleosome remodeling activities may change either the frequency or duration of the open periods (Tomschik et al. 2005).

Other groups have recently studied nucleosomes using FRET (Tóth et al. 2001, 2006, Bao et al. 2004, 2006, Li \& Widom 2004, Park et al. 2004, White \& Luger 2004, Li et al. 2005, Lovullo et al. 2005, 


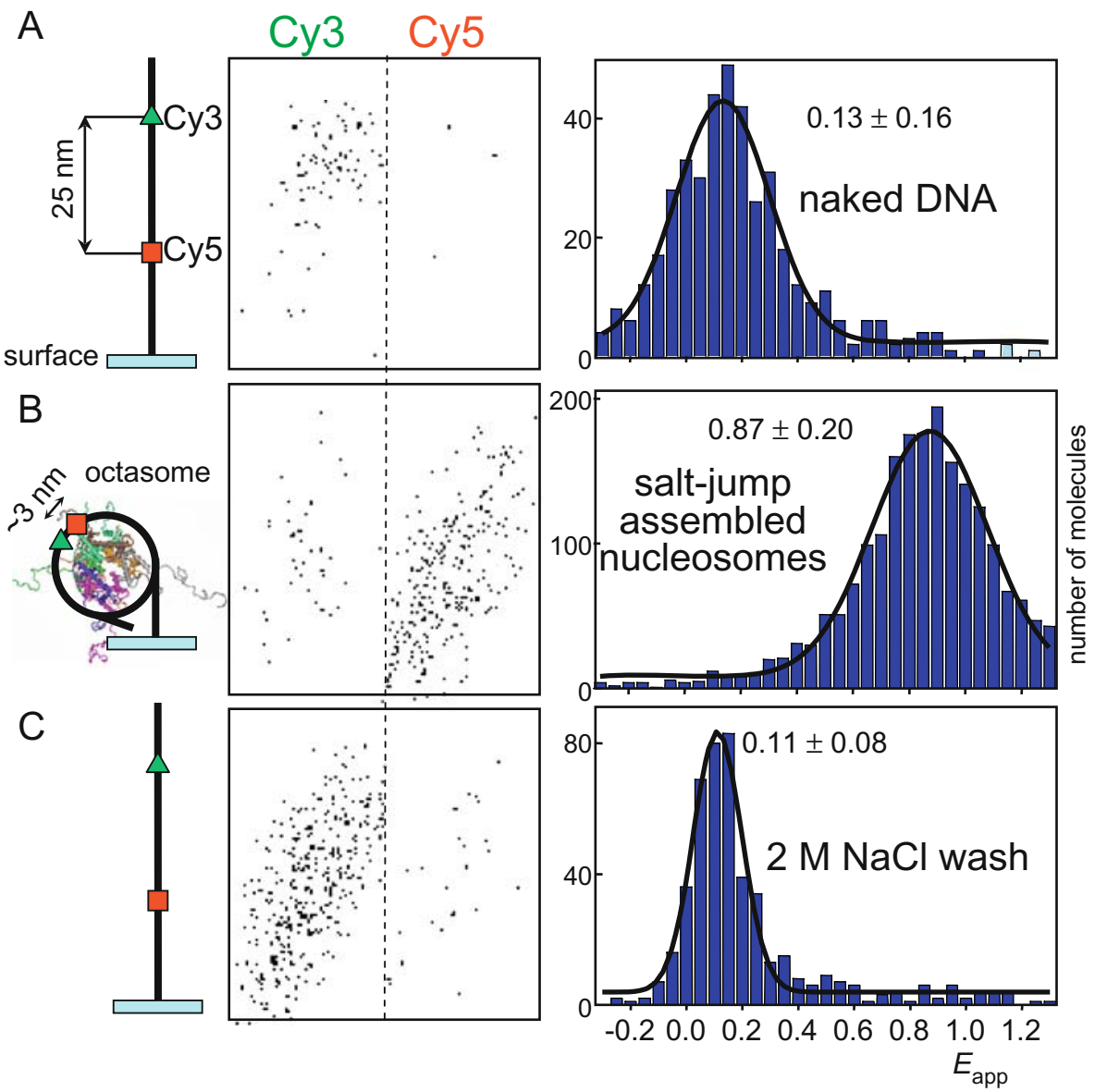

Figure 2. Evanescent-field fluorescence microscopy and FRET of naked DNA and reconstituted nucleosomes on fluorescently labeled DNA (Tomschik et al. 2005). (A) In naked DNA molecules, the two dyes are $\sim 25 \mathrm{~nm}$ apart and only the Cy3 filtered image exhibits much fluorescence intensity. The accompanying histogram centers at 0.13 apparent efficiency of FRET ( $\left.E_{\text {app }}\right)$ units. (B) In the reconstituted octasomes, the two dyes are within $\sim 3 \mathrm{~nm}$ and the Cy5 filtered image exhibits strong intensities with an accompanying histogram centered at $0.87 E_{\text {app }}$ units. (C) After a $2 \mathrm{M} \mathrm{NaCl}$ wash of the reconstituted nucleosomes, the remaining naked DNA exhibits high fluorescence intensities predominantly in the Cy3 filtered image with an accompanying histogram centered at $0.11 E_{\text {app }}$ units. The Cy3 and Cy5 images are shown in inverted contrast to better display the individual intensities (dark spots) against a white background.

Bussiek et al. 2006, Yang et al. 2006, Gansen et al. 2007, Hoch et al. 2007, Kelbauskas et al. 2007, 2008, Koopmans et al. 2007), although most experiments have been at the population level. In bulk FRET, an overall FRET signal is observed from a population of molecules. Addition of a factor or a change in conditions such as a change in overall ionic strength is measured by an irreversible shift in the total FRET signal. A limitation of experiments at the population level is that they do not allow observations of spontaneous, asynchronous, reversible events occurring in individual molecules.
Pioneers of the use of FRET to study nucleosomes (Tóth et al. 2001, 2006, Bussiek et al. 2006), Tóth and Langowski and co-workers have recently used spFRET with solution fluorescence correlation spectroscopy (FCS) to distinguish between two different histone octamer positions on the same DNA molecule (Gansen et al. 2007). Positioning the donor dye near the dyad and, one wrap away, placing the acceptor dye on the DNA leaving the nucleosome, van Noort and colleagues observed 3\% of their surface-tethered nucleosomes stochastically breathing (Koopmans et al. 2007). 


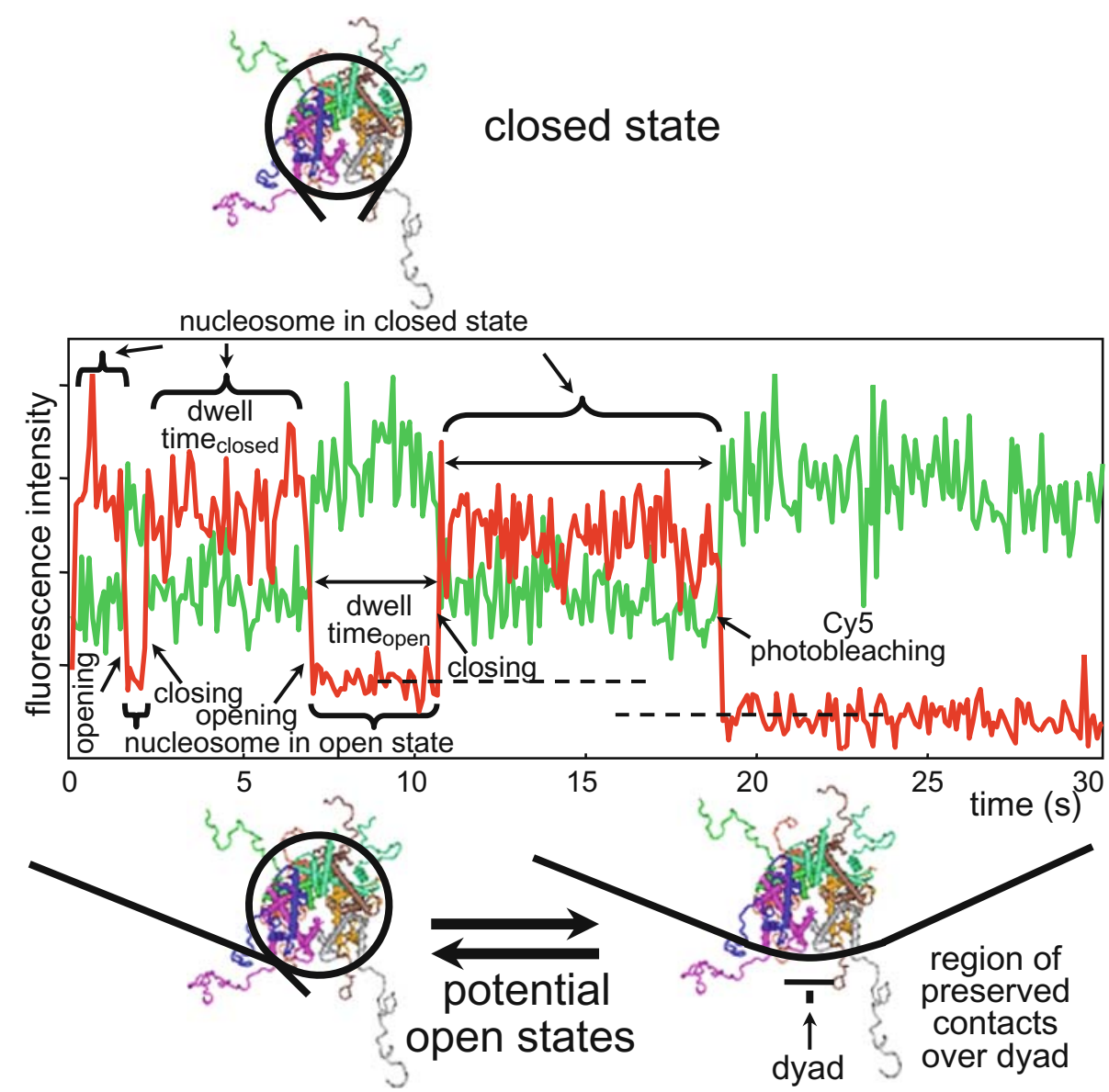

Figure 3. Example time trajectories of individual fluorophores from the image in Figure 2B (Tomschik et al. 2005). Green trajectory represents the intensities of donor $\mathrm{Cy} 3$ dye and the red trajectory represents the intensities of the cognate acceptor Cy5 dye (100 ms time points). The anti-correlation of the two trajectories indicates they come from the same DNA molecule. The intensities revert back and forth between two states, a high and low FRET state, before the Cy5 dye photobleaches. The intensity of Cy5 photobleaching is lower than the low state intensity, indicating that the observed low states are not from Cy5 photoblinking events. The length of time that the nucleosome resides or dwells in a low state or high state is indicated. Schematics of how the nucleosome might appear in the high state or the low state are shown above and below the time trajectories, respectively.

\section{The PcrA helicase of Gram-positive bacteria}

Destabilization of dsDNA is an essential step in DNA transactions such as replication, repair and recombination. DNA helicases are enzymes that catalyze the physical separation of the two strands of DNA required for processes where single-stranded DNA (ssDNA) is an intermediate (Lohman 1993). PcrA is a conserved helicase present in all Gram-positive bacteria sequenced so far. It belongs to the SF1 superfamily of helicases (Hall \& Matson 1999), which also includes the UvrD and Rep helicases of E. coli. It was first identified by Iordanescu in a genetic screen for chromosomally encoded genes that affected the rolling-circle replication of plasmid pT181 (Iordanescu 1993). Homologues of PcrA from various important pathogenic bacteria such as Staphylococcus aureus, Bacillus anthracis and Streptococcus pneumoniae have since been overexpressed as recombinant proteins in E. coli and biochemically characterized (Chang et al. 2002, Naqvi et al. 2003, Anand et al. 2004, Ruiz-Maso et al. 2006). The PcrA proteins from various bacteria share approximately $60 \%$ identity. Gene knockout studies in B. subtilis and $S$. pneumoniae have shown that the helicase is essential (Petit et al. 1998, Ruiz-Maso et al. 2006). 
Anti-sense inhibition studies have shown that pcrA knockout in S. aureus is not viable (Ji et al. 2001). The helicase fulfills functions in UV-repair as well as plasmid rolling-circle replication (Petit et al. 1998, Chang et al. 2002). The crystal structures of PcrA (Subramanya et al. 1996, Velankar et al. 1999), UvrD (Lee \& Yang 2006) and Rep (Korolev et al. 1997) are available. The crystal structure of the PcrA homologue of Bacillus stearothermophilus $\left(\mathrm{PcrA}_{B s t}\right)$ shows that the protein has four structural domains, termed 1A, 1B, 2A and 2B (Figure 4A) (Subramanya et al. 1996, Velankar et al. 1999). The conserved motifs involved in ATPase and ssDNA translocation are present in domains 1A and 2A (Velankar et al. 1999). PcrA $A_{B s t}$ prefers duplex DNA substrates containing a $3^{\prime}$ ss tail (Bird et al. 1998, Dillingham et al. 2000, 2002), whereas mesophilic PcrA homologues that have been studied so far prefer a $5^{\prime}$ ss tail folded into stem-loop structures (Naqvi et al. 2003, Anand \& Khan 2004, Ruiz-Maso et al. 2006). Replication of chromosomal DNA is only slightly affected in conditional knockouts of pcrA in B. subtilis, suggesting that it is not the major replicative helicase (Petit et al. 1998). Suppressor mutants for PcrA knockouts in $B$. subtilis map in $\mathrm{recF}$, recO and $\mathrm{recR}$ genes whose products are involved in promoting recAdependent homologous recombination (Shan et al. 1997, Bork et al. 2001b, Petit \& Ehrlich 2002, Morimatsu \& Kowalczykowski 2003). In the absence of PcrA, unregulated formation of recombination intermediates may be toxic to the cell (Petit \& Ehrlich 2002). This suggested that an interaction between PcrA and these proteins is essential for supporting cell viability.

\section{The Rep helicase of $E$. coli}

The Rep protein of E. coli was the first helicase to be characterized (Denhardt et al. 1967). This helicase is required for the replication of single-stranded DNA bacteriophages M13 and $\phi$ X174 in E. coli (Denhardt
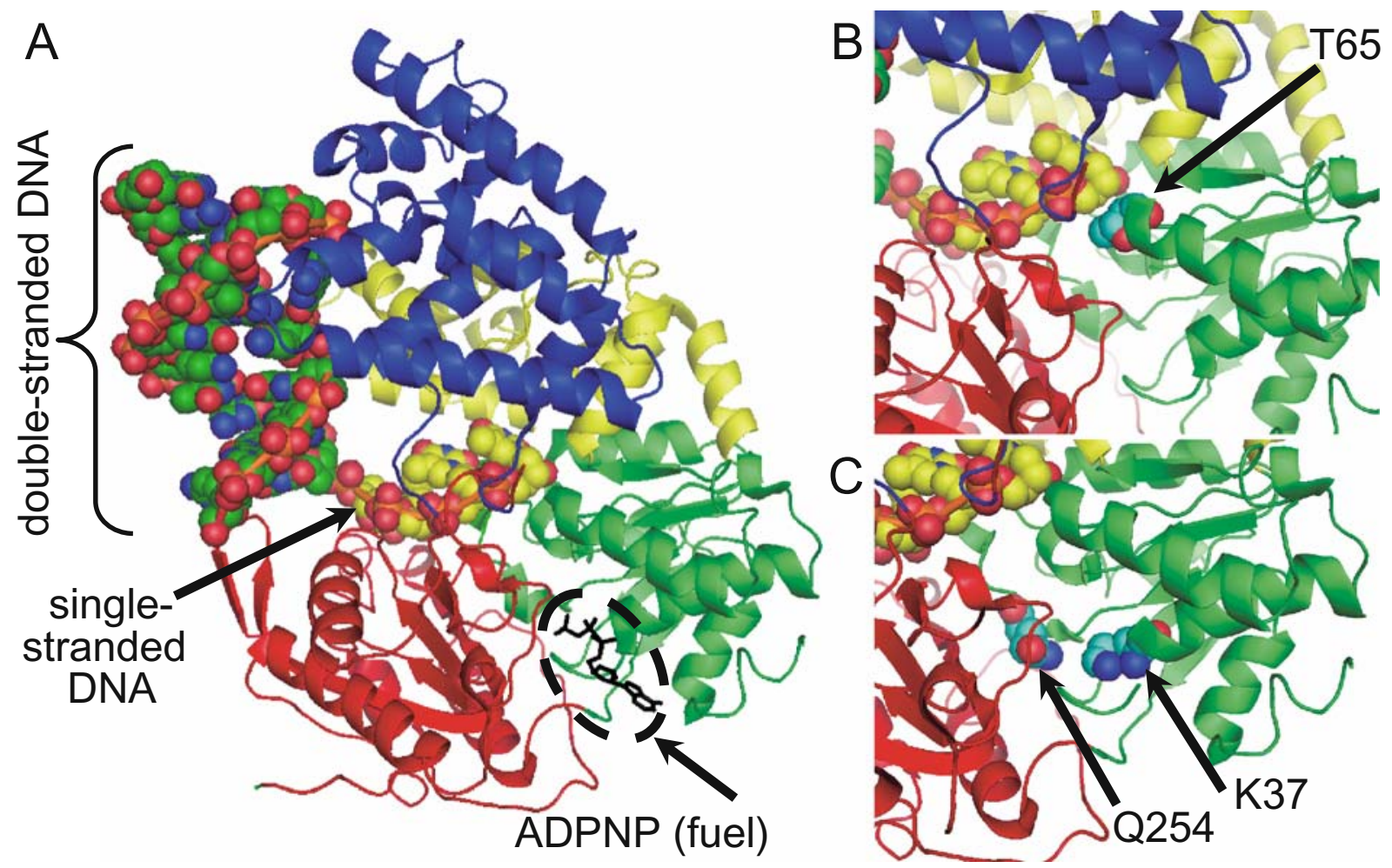

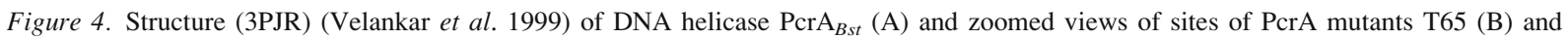
Q254 K37 (C). We made the corresponding changes (T61I for PcrA3, Q250R K33A for PcrAH') in PcrA sau. Models displayed in PyMOL (DeLano 2002). Experiments performed on either of the mutants do not detect ATPase hydrolysis and helicase activity, indicating that the mutations interfere with these functions (Anand et al. 2007). 
et al. 1972, Eisenberg et al. 1977, Scott et al. 1977). The precise role of Rep helicase in host DNA metabolism remains to be fully elucidated. However, replication fork progression is slowed in rep mutants, suggesting a role for Rep helicase in DNA replication (Lane \& Denhardt 1975) in spite of not being the major replicative helicase. The Rep helicase shares $40 \%$ identity with the E. coli UvrD helicase. E. coli rep mutants are viable (Colasanti \& Denhardt 1987), whereas $E$. coli rep uvrD double mutants are not (Taucher-Scholtz et al. 1983). Moreover, E. coli rep $u v r \mathrm{D}$ double mutants can be complemented by $p c r \mathrm{~A}$, suggesting a common role for these helicases in DNA transactions (Petit et al. 1998). Despite some similarities, there are also differences among these three helicases. For example, the UV repair defect of E. coli uvrD mutant is complemented by B. subtilis pcrA but not by E. coli rep (Petit et al. 1998). Similarly, UvrD efficiently dismantles RecA-DNA filaments, whereas Rep has only a marginal activity (Veaute et al. 2005). Moreover, UvrD but not Rep prevents homologous recombination in vivo (Veaute et al. 2005). As observed in an spFRET-based assay, Rep undergoes repetitive shuttling on ssDNA close to blockades such as ssDNA/dsDNA junctions (Myong et al. 2005). Curiously, the biological relevance of this activity remains unknown. Preliminary evidence suggests that Rep could reduce DNA binding efficiencies by proteins such as RecA by this activity as described later (Myong et al. 2005).

\section{The bacterial recombination protein RecA}

RecA is a conserved protein present in bacteria and its homologues are ubiquitous (Roca \& Cox 1997, Cox 2003). Clark and Margulies discovered RecA in a genetic screen for mutants defective in recombination and UV repair (Clark \& Margulies 1965). RecA is essential for DNA recombination and mediates the SOS response upon DNA damage (Kowalczykowski 1991, Cox 2003, 2007, McGrew \& Knight 2003). A nucleoprotein complex formed by RecA catalyzes DNA strand exchange (Kowalczykowski 1991, Cox 2003, McGrew \& Knight 2003). Assembly of E. coli RecA protein $\left(\operatorname{Rec} A_{E c o}\right)$ on DNA is favored by ATP, dATP and ATP $\gamma$ S (Kowalczykowski 1991, Cox 2003, McGrew \& Knight 2003). RecA $A_{E c o}$ polymerizes in the $5^{\prime}$ to $3^{\prime}$ direction on DNA and depolymerizes predominantly in the same direction
(Register \& Griffith 1985, Bork et al. 2001a). The crystal structures of RecA from E. coli and various bacterial homologues are known (Story et al. 1992, Datta et al. 2000, Rajan \& Bell 2004, Krishna et al. 2006), and they highlight the importance of intersubunit contacts in the RecA filament. Unregulated recombination is harmful and, therefore, various mechanisms exist to regulate recombination inside the cells (Watt et al. 1995, Chanet et al. 1996, Aguilera 2001, Myung et al. 2001, Petit \& Ehrlich 2002, Traverso et al. 2003, Veaute et al. 2005, Kang \& Blaser 2006). RecA forms characteristic striated filaments in negatively stained electron micrographs (Stasiak et al. 1981). Thus, the displacement of RecA from ssDNA by UvrD helicase has been demonstrated by electron microscopy (Veaute et al. 2005). However, the advent of sensitive single-molecule approaches has allowed measurements of RecA dynamics in real time (Leger et al. 1998, Bennink et al. 1999, Hegner et al. 1999, Shivashankar et al. 1999, Fulconis et al. 2004, 2006, Galletto et al. 2006, Joo et al. 2006, Li et al. 2006) without the need to fix the samples. Here we will describe two spFRET-based methods for studying RecA dynamics on ssDNA and dsDNA. Single-molecule imaging allowed testing of these hypotheses.

\section{An spFRET-based assay to monitor RecA binding and its displacement from ssDNA}

Rep helicase harbors high affinity for $3^{\prime}$ tailed duplex substrates. Therefore, the $\mathrm{Ha}$ group designed a duplex DNA substrate (20 bases) that had a $3^{\prime}$ overhang $\left(\mathrm{dT}_{40}\right)$. They placed a donor dye $(\mathrm{Cy} 3)$ at the $3^{\prime}$ end of the overhang and an acceptor dye (Cy5) at the ss/ds junction of the substrate (Figure 5A). Because ssDNA is much more flexible than dsDNA, the free substrate exhibits high FRET as the donor and acceptor dyes are often in close proximity (Figure 5B). RecA-DNA filaments are rigid. Therefore, formation of RecA-DNA complex at the ss portion of the substrate would make the DNA rigid and straight (Figure 5C) and keep the dyes apart. As a result, in the presence of the RecA protein, nearly all of the fluorescently labeled tailed duplex substrate would exhibit a low FRET (Figure 5D, compare the upper panel versus the lower panel) (Myong et al. 2005). Thus, the binding of RecA to ssDNA can be followed using a simple substrate dual-labeled 


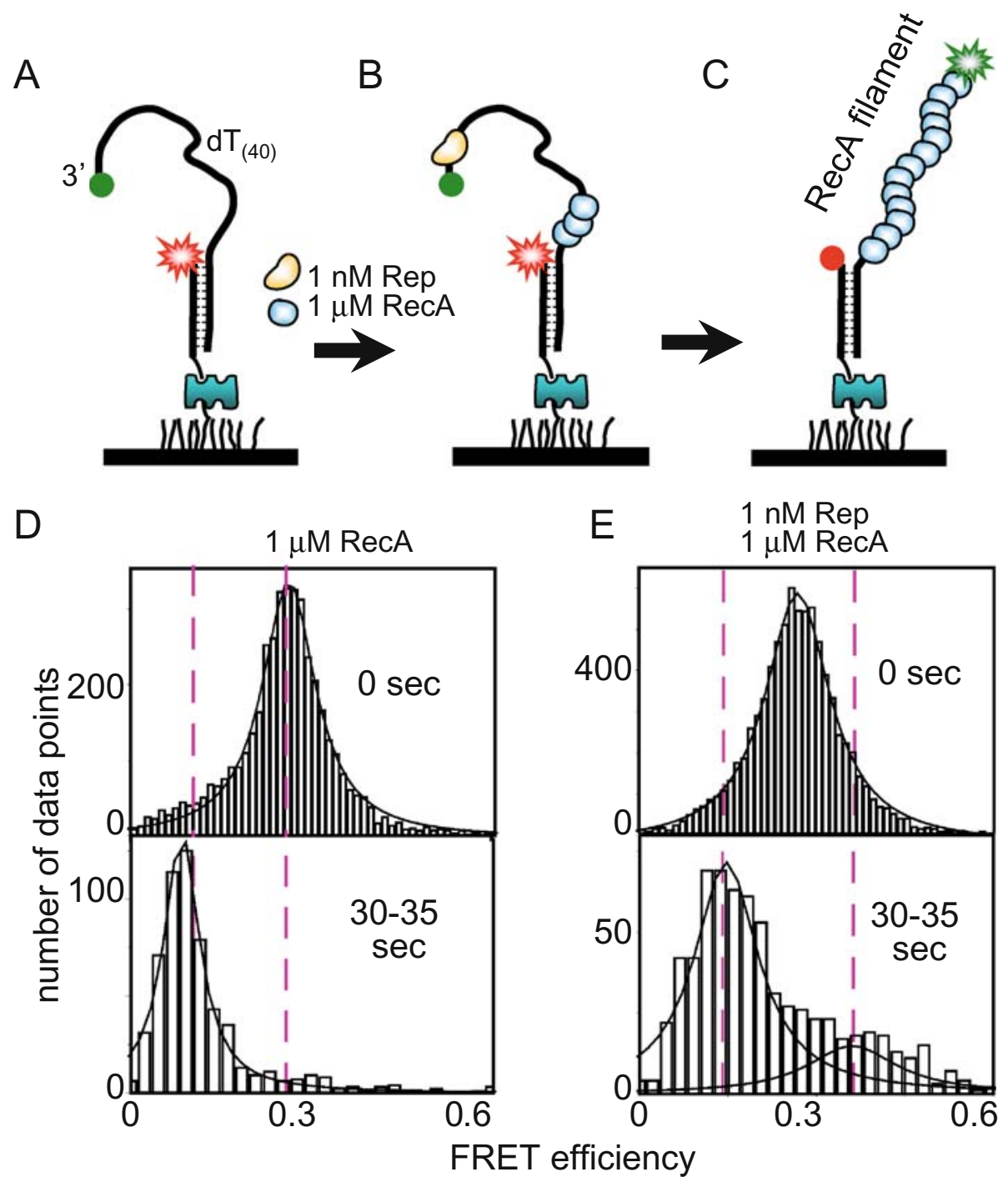

Figure 5. Rep helicase inhibits assembly of RecA on ssDNA. (A) Schematic of experimental system. A dsDNA molecule with a $3^{\prime}$ dT 40 tail is secured via a $3^{\prime}$ biotinylated end/streptavidin to a polyethylene glycol surface, which promotes reduction of nonspecific protein binding. The shorter oligonucleotide is labeled with an acceptor Cy5 dye and the $3^{\prime}$ end of the $\mathrm{dT}_{40}$ tail has a donor Cy3 dye. (B and C) Upon binding of RecA, the protein forms a filament on the ssDNA molecule with concomitant increasing distance between the two dyes leading to low FRET. Added Rep DNA helicase can displace the RecA filament and maintain the higher FRET signal. (C) Time dependent experiment upon the addition of RecA. At zero time, the upper histogram centers at 0.3 FRET units, whereas by 30-35 seconds the lower histogram centers at a lower FRET peak. (D) Time dependent experiment upon the addition of RecA and Rep. At zero time, the upper histogram centers at 0.3 FRET units whereas by 30-35 seconds, the lower histogram has a lower FRET peak (as in C, lower histogram) and, additionally, a second peak with even higher FRET. The occurrence of the second peak suggests that Rep helicase inhibits RecA filament formation on the DNA molecule. (A-C) redrawn from Figure 3 of Myong et al. 2005; (D, E) drawn from data from Figure 3 of Myong et al. 2005 with permission.

with fluorescent dyes. When RecA assembly was carried out in the presence of the Rep helicase, the proportion of DNA molecules that showed a conversion from high FRET to low FRET was low (Figure 5E). Since Rep helicase harbored the ability to undergo repetitive shuttling on ssDNA, these results suggested that the Rep helicase was probably preventing the assembly of RecA on the DNA by continuously translocating back and forth on the ssDNA substrate (Myong et al. 2005). Thus, dual-labeled 
DNA substrates can be successfully used to demonstrate assembly and removal of RecA from ssDNA by following FRET signals.

\section{PcrA inhibits RecA mediated DNA strand exchange}

Biochemical studies showed that PcrA inhibits RecA-mediated DNA strand exchange and displaces RecA from both ssDNA and dsDNA (Anand et al. 2007). Additionally, these studies showed that the helicase activity of PcrA is not required for these functions (Anand et al. 2007). These studies used two well-defined site-directed mutants of PcrA. In one mutant, $\mathrm{PcrAH}^{-}$, the alteration of two amino acids (Q250R, K33A) in the Walker Box I and II motifs adversely affected its ATPase and helicase activities (Anand et al. 2004, 2007) (Figure 4B). The second mutant, pcrA3 (PcrA T61I), was able to support cell survival but was unable to support the rolling circle (RC) replication of the pT181 plasmid in S. aureus (Iordanescu 1993) (Figure 4C). Interestingly, the recombinant PcrA $3_{\text {Sau }}$ protein was defective in its ATPase and helicase activities, and predicted to be impaired in its DNA translocation activity, which requires ATP hydrolysis (Anand et al. 2005). Thus, we hypothesized that the helicase/ translocation activity of PcrA may be dispensable for the survival of $S$. aureus. These results were contrary to what is known for some other helicases belonging to superfamily 1 (SF1) such as the Escherichia coli UvrD and Rep helicases and the yeast Srs2 helicase, which have been shown to displace RecA or its eukaryotic homologue Rad51 from the DNA (Krejci et al. 2003, Veaute et al. 2003, 2005, Myong et al. 2005, Anand et al. 2007). There were two plausible explanations for helicaseindependent displacement of RecA by PcrA. One obvious explanation was direct competition for DNA binding sites between PcrA and RecA. However, in all biochemical assays PcrA was added after formation of the RecA filaments, thus ruling out this possibility. The second explanation was direct protein-protein interactions between PcrA and RecA somehow leading to the destabilization of RecA from the DNA. However, the nonstoichiometric nature of RecA inhibition (around one molecule of PcrA for ten molecules of RecA) argued for a catalytic mechanism.

\section{A spFRET based assay to monitor RecA assembly and displacement from dsDNA}

PcrA is an ssDNA translocase (Velankar et al. 1999, Dillingham et al. 2000), and it cannot access ds regions of a substrate without unwinding DNA. RecA can extend its polymerization into neighboring dsDNA in the $5^{\prime}$ to $3^{\prime}$ direction (Lindsley \& Cox 1990). Thus, we needed an approach to test destabilization of RecA from ds regions of the DNA not directly accessible by the helicase mutants of PcrA, which do not unwind dsDNA. We developed a novel spFRET based assay to monitor assembly of RecA on dsDNA and its subsequent displacement by PcrA. We utilized the principle of binding of RecA to dsDNA that is known to increase the length of dsDNA 1.5-fold (Stasiak et al. 1981). The high FRET signal of an appropriately placed dye pair in B-DNA would decrease upon lengthening of the DNA brought about by the binding of RecA. Likewise, displacement of RecA from the DNA would return the DNA molecule to its original naked $\mathrm{B}$-form and regain the higher FRET signal. We used a synthetic tailed duplex substrate (134 bp with a $(\mathrm{dT})_{20}$ ss tail) containing four equally placed Cy3/ Cy5 FRET pairs (Anand et al. 2007). The $20 \mathrm{nt}$ ssDNA tail served as the major site for nucleation of RecA, after which it could extend into the neighboring $\mathrm{ds}$ region as the polymerization of RecA proceeds in a $5^{\prime}$ to $3^{\prime}$ direction. A single biotin at the $5^{\prime}$ end of the tailed duplex allowed the substrate to be immobilized on the quartz surface. The assay was performed in quartz flow-cells coated with streptavidin as described (Zheng et al. 2005, Anand et al. 2007). The individual FRET pairs were $33 \mathrm{bp}(\sim 11 \mathrm{~nm})$ apart to prevent FRET among the pairs. Additionally, the order of the dyes forming the individual FRET pairs was reversed to increase the effective physical separation of the donor dyes from any acceptor dye other than the intended one. The molecules were visualized with an evanescent-field fluorescent microscope (Zheng et al. 2005), and analysis of the data was carried out using the Origin software (Zheng et al. 2005, Anand et al. 2007).

Naked DNA molecules exhibited high FRET (Figure 6). A video snapshot showing several individual molecules of DNA from the actual experiment is shown in Figure 6. RecA binding to the substrate decreased the mean apparent efficiency of FRET $\left(E_{\text {app }}\right)$ from 0.8 to 0.35 owing to lengthening of the 
A naked DNA

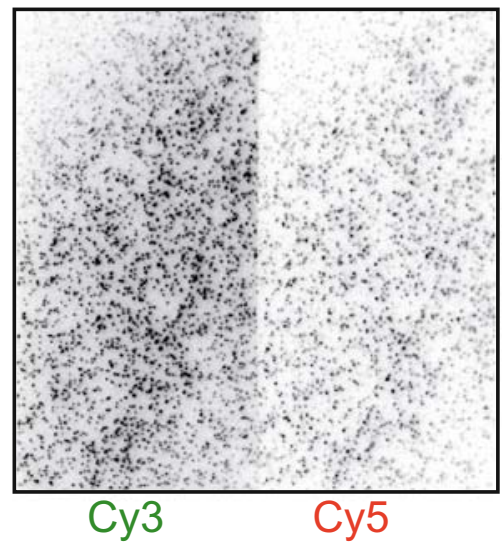

B $\quad \operatorname{RecA}+$ DNA

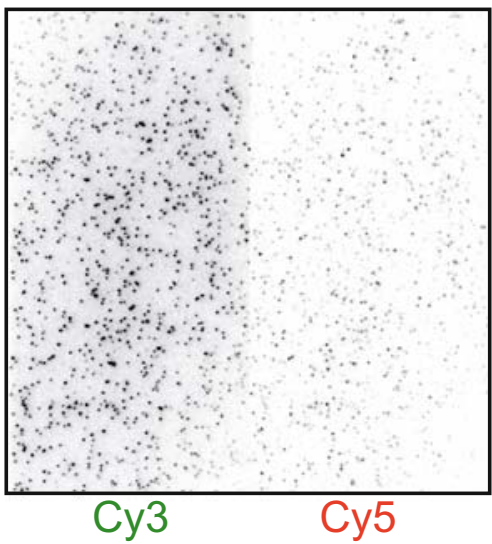

$\operatorname{Rec} A$

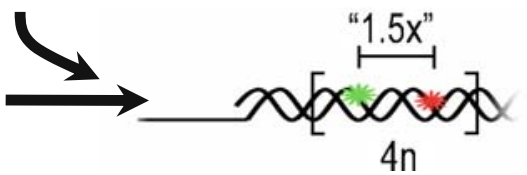

$4 \mathrm{n}$
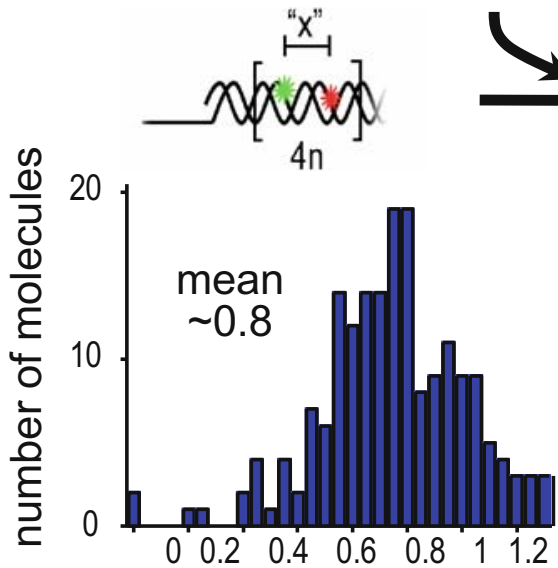

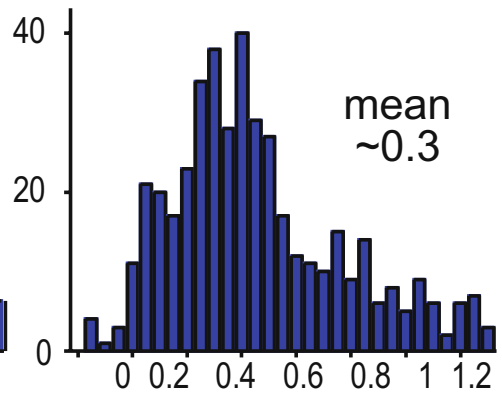

C RecA + DNA + PcrA

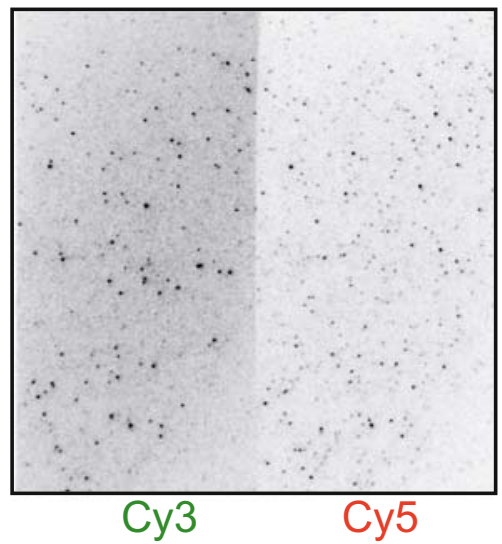

PcrA
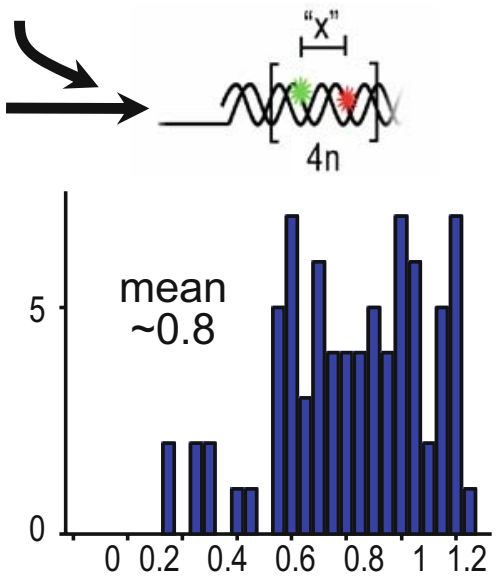

\section{apparent efficiency of $\operatorname{FRET}\left(E_{\text {app }}\right)$}

Figure 6. PcrA DNA helicase reverses RecA induced dsDNA lengthening. The chematics between the images and the histograms indicate the order of the reactions. (A) Donor Cy3/acceptor Cy5 filtered wide-field evanescent-field fluorescence microscope images of naked DNA molecules. The two dyes are $13 \mathrm{bp}(13 \mathrm{bp} \times 0.34 \mathrm{~nm} / \mathrm{bp} \not \subset 4.42 \mathrm{~nm})$ apart and exhibit high FRET with mean $E_{\text {app }}$ of $\sim 0.8$ units in the accompanying histogram. (B) Related images of the DNA molecules in (A) mixed with RecA which form filaments on the doubled-stranded molecule and lengthen it 1.5 -fold. Now the dyes are about $6.63 \mathrm{~nm}$ apart with a corresponding drop in FRET in the accompanying histogram with a mean of $\sim 0.3 E_{\text {app }}$ units. (C) Related images of the DNA/RecA complexes in (B) mixed with PcrA DNA helicase. The accompanying histogram has a mean of $0.8 E_{\text {app }}$ units, indicating that the helicase has displaced the RecA proteins and the DNA molecules have regained their original B-form structure of $0.34 \mathrm{~nm} / \mathrm{bp}$. Intriguingly, using the formula $E_{\mathrm{FRET}}=1 /\left(1+\left(R / R_{0}\right)^{6}\right)$, we can calculate an $E_{\mathrm{FRET}}$ value of 0.86 for the $4.42 \mathrm{~nm}\left(13 \mathrm{bp}\right.$ ) high FRET distance and $E_{\mathrm{FRET}}$ of 0.35 for the $6.63 \mathrm{~nm}$ low FRET distance, and these calculated values are in general agreement with the measured mean $E_{\mathrm{FRET}}$ values of $\sim 0.8$ and $\sim 0.3$ despite the fact that the dyes are attached to the bases on carbon linkers. Histograms and order of addition schematic adapted from (Anand et al. 2007).

DNA and the concomitant increase in distance separating the individual FRET pairs (from $\sim 4.4 \mathrm{~nm}$ to $\sim 6.6 \mathrm{~nm}$ ). In the image, one can readily visualize this by the dramatic reduction in fluorescence arising from the Cy5 channel. This reduction in FRET was stable for the period of the experiment (at least up to
$30 \mathrm{~min})$. Upon addition of PcrA, there was a reversal in the mean $E_{\text {app }}$ to $\sim 0.8$ (Figure 6), indicating removal of RecA by PcrA. Removal of RecA and concomitant reversal of FRET values can also be readily visualized on the screen as $\mathrm{Cy} 5$ fluorescence intensities increase again. We used a similar assay to 
compare the efficiency of RecA displacement by wild-type $\operatorname{PcrA}_{S a u}$ and its helicase mutants. We observed no noticeable differences in the RecA displacement activity of PcrA $\mathrm{Sau}_{\text {, }}$ PcrA3 and PcrAH ${ }^{-}$. Thus, the spFRET-based assay helped us to demonstrate that the helicase activity of PcrA is not required for displacing RecA from dsDNA. Further, the assay conveniently demonstrated displacement of RecA from the ds portion of the substrate, which is not physically accessible to the helicase mutants of PcrA.

\section{Mechanism of RecA displacement from DNA}

The results of RecA displacement by PcrA, UvrD and Rep suggest that bacterial helicases can utilize both translocation-dependent and translocation-independent mechanisms to regulate the function of the bacterial recombination protein RecA (Krejci et al. 2003, Veaute et al. 2003, 2005, Myong et al. 2005, Anand et al. 2007). Since the ATPase mutants of PcrA, which lack helicase and translocation activities, displace RecA from the DNA, we hypothesize

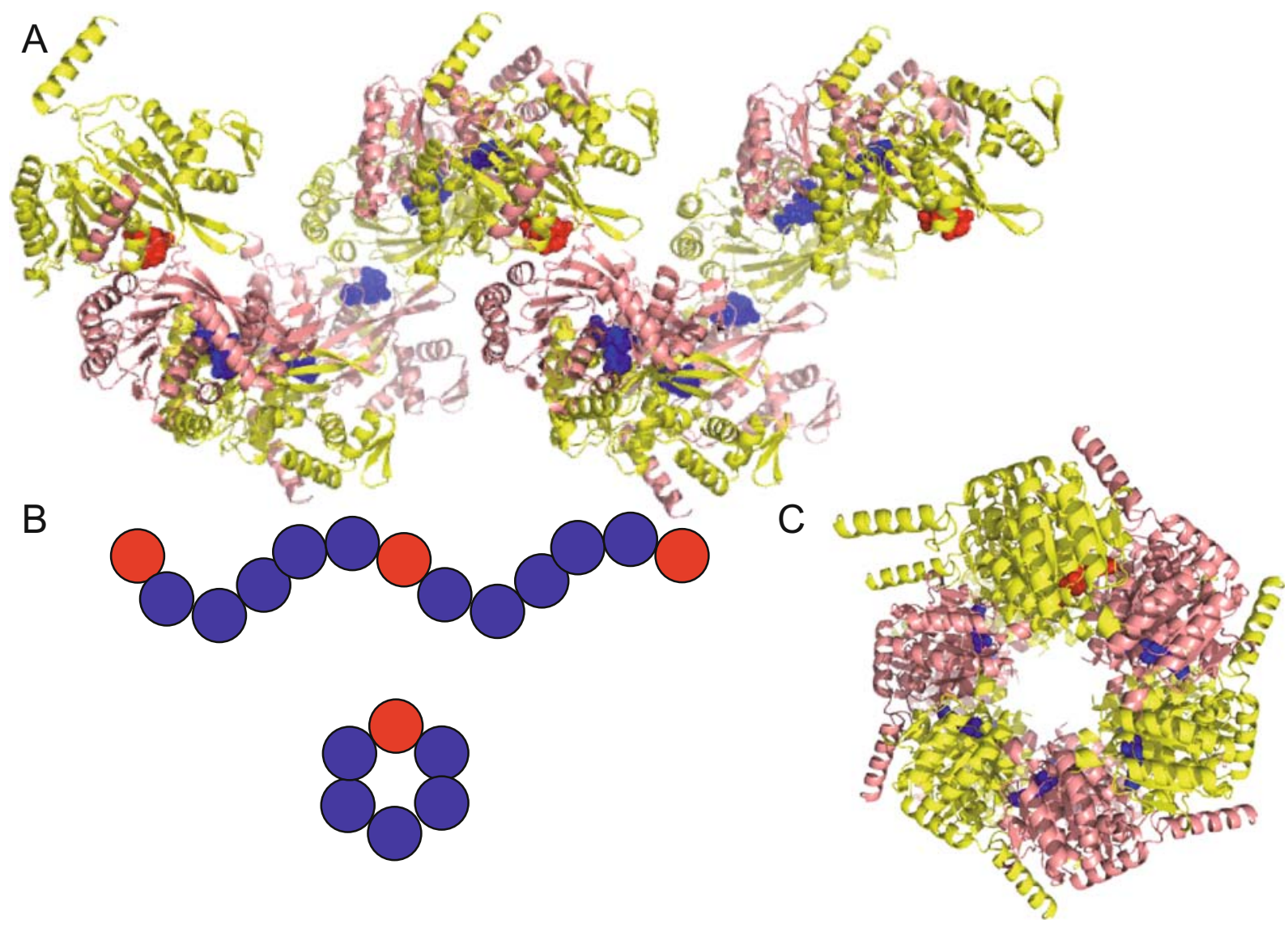

Figure 7. (A) Hydrolysis of ATP occurs in waves in the RecA-DNA filament. In this image, the first, seventh and thirteenth RecA monomers have ADP in red, and the remainder have ATP in blue. The RecA subunits are colored alternately with yellow and salmon to distinguish them. ATP hydrolysis within a RecA filament is coordinated such that the first, seventh and thirteenth RecA subunits hydrolyze ATP at the same time. (B) The upper schematic shows the subunit organization of the RecA filament depicted in $7 \AA$. The red and blue spheres indicate RecA-ADP and RecA-ATP, respectively. The lower schematic indicates the subunit organization of the RecA filament viewed along its vertical axis as shown in Figure 7C. There are 6 RecA subunits per turn of the RecA-DNA helical filament. Only one-in-six RecA subunits in a filament hydrolyze ATP at the same time. These subunits align along the same face of the RecA filament. Figure inspired by and adapted from Cox et al. (2005). (C) The structure of a RecA filament viewed along its vertical axis. ADP is depicted with red spheres, ATP with blue spheres, and the RecA monomers are ribbon figures alternating in color between yellow and salmon. Models in (A) and (C) displayed in PyMOL (DeLano 2002). 
that PcrA may utilize the inherent cooperativity of RecA monomers within its filament to cause its disassembly from the DNA. The speculated mechanism would increase the efficiency of RecA displacement by PcrA, which is a non-processive monomeric helicase. Several biochemical studies have shown that the ATPase activity of RecA is highly cooperative (Cox et al. 2005). The residues responsible for propagating intersubunit cooperativity have been mapped (Kelley De Zutter et al. 2001, McGrew \& Knight 2003). The Cox group has shown that RecA hydrolyzes ATP in waves with the subunits registered on the same surface of the filament hydrolyzing ATP at the same time (Figure 7). These results are captured in the elegant model first described by Cox (Cox et al. 2005) and recapitulated here for discussion.

RecA/DNA complexes assembled in the presence of ATP $\gamma \mathrm{S}$ and dATP are highly stable and also resistant to displacement by helicase mutants of PcrA (Anand et al. 2007), lending credence to the possibility that PcrA could utilize the ATPase activity of RecA to trigger its own collapse from the DNA. Thus, in one model of RecA displacement, PcrA could trigger an allosteric switch on RecA, which would be propagated to neighboring subunits of RecA through the cooperativity that exists in RecA filaments. Contact of one molecule of PcrA with one RecA molecule could trigger the collapse of an entire RecA filament. This model can easily be tested by a spFRET-based assay described earlier by studying the kinetics of reappearance of FRET from RecA-DNA complexes in the presence of PcrA and its helicase mutants. Polymerization of the RecA filament along the DNA molecule or the displacement of the RecA monomers by a processive DNA helicase can be observed as the change in four FRET pairs in real time; the distance between two independent changes in FRET occurring at the same microscopic location could indicate the duration of time for one process as it proceeds from one FRET pair to the next FRET pair on the same DNA molecule. These experiments are currently in progress in our laboratory.

spFRET-based studies on helicases will increase the sensitivity of methods used to study helicases and dramatically increase our understanding of the behavior of helicases. These experiments should also lead to the discovery of new behaviors, which could otherwise go unnoticed using conventional methods such as traditional biochemistry and electron microscopy. However, understanding of the biological relevance of the observations made using powerful biophysical methods requires testing of the models generated from such studies in vivo using genetic approaches. For example, current biochemical evidence suggests that the helicase activity of PcrA is not essential for the regulation of recombination in S. aureus (Anand et al. 2007). However, more genetic studies are required to prove unequivocally that this is indeed the case in vivo. Likewise, genetic studies have shown that the ability of the E. coli Rep helicase to regulate RecA function is not essential for E. coli (Colasanti \& Denhardt 1987). Thus, the biological function of prevention of RecA assembly on DNA by Rep helicase requires further investigation.

\section{Acknowledgements}

We thank Dr J. van Noort for sharing experimental results prior to publication and Dr R. Steinman for critical reading of the manuscript. This work was supported by NIH grants GM031685 and AI064941 (S.A.K.) and GM077872 (S.H.L.).

\section{References}

Aguilera A (2001) Double-strand break repair: are Rad51/ RecA-DNA joints barriers to DNA replication? Trends Genet 17: 318-321.

Anand SP, Khan SA (2004) Structure-specific DNA binding and bipolar helicase activities of PcrA. Nucleic Acids Res 32: 3190-3197.

Anand SP, Mitra P, Naqvi A, Khan SA (2004) Bacillus anthracis and Bacillus cereus PcrA helicases can support DNA unwinding and in vitro rolling-circle replication of plasmid pT181 of Staphylococcus aureus. J Bacteriol 186: 2195-2199.

Anand SP, Chattopadhyay A, Khan SA (2005) The PcrA3 mutant binds DNA and interacts with the RepC initiator protein of plasmid pT181 but is defective in its DNA helicase and unwinding activities. Plasmid 54: 104-113.

Anand SP, Zheng H, Bianco PR, Leuba SH, Khan SA (2007) DNA helicase activity of PcrA is not required for the displacement of RecA protein from DNA or inhibition of RecA-mediated strand exchange. J Bacteriol 189: 4502-4509.

Arents G, Burlingame RW, Wang BC, Love WE, Moudrianakis EN (1991) The nucleosomal core histone octamer at 3.1 A resolution: a tripartite protein assembly and a left-handed superhelix. Proc Natl Acad Sci U S A 88: 10148-10152. 
Axelrod D (1981) Cell-substrate contacts illuminated by total internal reflection fluorescence. J Cell Biol 89: 141-145.

Bao Y, Konesky K, Park YJ, et al. (2004) Nucleosomes containing the histone variant H2A.Bbd organize only 118 base pairs of DNA. EMBO J 23: 3314-3324.

Bao Y, White CL, Luger K (2006) Nucleosome core particles containing a poly(dA.dT) sequence element exhibit a locally distorted DNA structure. J Mol Biol 361: 617-624.

Baum WA (1962) Problems of extra-galactic research. In: McVittie GC, ed. IAU Symposium No. 15, p. 390.

Bennink ML, Schärer OD, Kanaar R et al. (1999) Single-molecule manipulation of double-stranded DNA using optical tweezers: interaction studies of DNA with RecA and YOYO-1. Cytometry 36: 200-208.

Bird LE, Brannigan JA, Subramanya HS, Wigley DB (1998) Characterisation of Bacillus stearothermophilus PcrA helicase: evidence against an active rolling mechanism. Nucleic Acids Res 26: $2686-2693$.

Bork JM, Cox MM, Inman RB (2001a) RecA protein filaments disassemble in the $5^{\prime}$ to $3^{\prime}$ direction on single-stranded DNA. J Biol Chem 276: 45740-45743.

Bork JM, Cox MM, Inman RB (2001b) The RecOR proteins modulate RecA protein function at $5^{\prime}$ ends of single-stranded DNA. EMBO J 20: 7313-7322.

Brower-Toland BD, Smith CL, Yeh RC, Lis JT, Peterson CL, Wang MD (2002) Mechanical disruption of individual nucleosomes reveals a reversible multistage release of DNA. Proc Natl Acad Sci U S A 99: 1960-1965.

Bussiek M, Tóth K, Schwarz N, Langowski J (2006) Trinucleosome compaction studied by fluorescence energy transfer and scanning force microscopy. Biochemistry 45: 10838-10846.

Chanet R, Heude M, Adjiri A, Maloisel L, Fabre F (1996) Semidominant mutations in the yeast Rad51 protein and their relationships with the Srs2 helicase. Mol Cell Biol 16: 4782-4789.

Chang TL, Naqvi A, Anand SP, Kramer MG, Munshi R, Khan SA (2002) Biochemical characterization of the Staphylococcus aureus PcrA helicase and its role in plasmid rolling circle replication. J Biol Chem 277: 45880-45886.

Clark AJ, Margulies AD (1965) Isolation and characterization of recombination-deficient mutants of Escherichia coli K12. Proc Natl Acad Sci U S A 53: 451-459.

Claudet C, Bednar J (2006) Pulling the chromatin. Eur Phys J E Soft Matter 19: 331-337.

Clegg RM (1992) Fluorescence resonance energy transfer and nucleic acids. Methods Enzymol 211: 353-388.

Clegg RM (1995) Fluorescence resonance energy transfer. Curr Opin Biotechnol 6: 103-110.

Colasanti J, Denhardt DT (1987) The Escherichia coli rep mutation. X. Consequences of increased and decreased Rep protein levels. Mol Gen Genet 209: 382-390.

Cox JM, Tsodikov OV, Cox MM (2005) Organized unidirectional waves of ATP hydrolysis within a RecA filament. PLoS Biol 3: e52.

Cox MM (2003) The bacterial RecA protein as a motor protein. Annu Rev Microbiol 57: 551-577.

Cox MM (2007) Regulation of bacterial RecA protein function. Crit Rev Biochem Mol Biol 42: 41-63.

Datta S, Prabu MM, Vaze MB et al. (2000) Crystal structures of Mycobacterium tuberculosis RecA and its complex with ADP-
$\mathrm{AlF}(4)$ : implications for decreased ATPase activity and molecular aggregation. Nucleic Acids Res 28: 4964-4973.

Davey CA, Sargent DF, Luger K, Maeder AW, Richmond TJ (2002) Solvent mediated interactions in the structure of the nucleosome core particle at $1.9 \AA$ resolution. $J$ Mol Biol 319: 1097-1113.

DeLano WL (2002) The PyMOL Molecular Graphics System. San Carlos: DeLano Scientific.

Denhardt DT, Dressler DH, Hathaway A (1967) The abortive replication of phiX174 DNA in a recombination-deficient mutant of Escherichia coli. Proc Natl Acad Sci U S A 57: 813-820.

Denhardt DT, Iwaya M, Larison LL (1972) The rep mutation. II. Its effect on Escherichia coli and on the replication of bacteriophage phi X174. Virology 49: 486-496.

Deniz AA, Mukhopadhyay S, Lemke EA (2008) Single-molecule biophysics: at the interface of biology, physics and chemistry. $J R$ Soc Interface 5: 15-45.

Dillingham MS, Wigley DB, Webb MR (2000) Demonstration of unidirectional single-stranded DNA translocation by PcrA helicase: measurement of step size and translocation speed. Biochemistry 39: 205-212.

Dillingham MS, Wigley DB, Webb MR (2002) Direct measurement of single-stranded DNA translocation by PcrA helicase using the fluorescent base analogue 2-aminopurine. Biochemistry 41: 643-651.

Eisenberg S, Griffith J, Kornberg A (1977) phiX174 cistron A protein is a multifunctional enzyme in DNA replication. Proc Natl Acad Sci U S A 74: 3198-3202.

Förster T (1959) 10th Spiers Memorial Lecture. Transfer mechanisms of electronic excitation. Discuss Faraday Soc 27: 7-17.

Fulconis R, Bancaud A, Allemand JF, Croquette V, Dutreix M, Viovy JL (2004) Twisting and untwisting a single DNA molecule covered by RecA protein. Biophys $J$ 87: 2552-2563.

Fulconis R, Mine J, Bancaud A, Dutreix M, Viovy JL (2006) Mechanism of RecA-mediated homologous recombination revisited by single molecule nanomanipulation. EMBO $J \mathbf{2 5}$ : 4293-4304.

Galletto R, Amitani I, Baskin RJ, Kowalczykowski SC (2006) Direct observation of individual RecA filaments assembling on single DNA molecules. Nature 443: 875-878.

Gansen A, Hauger F, Tóth K, Langowski J (2007) Single-pair fluorescence resonance energy transfer of nucleosomes in free diffusion: optimizing stability and resolution of subpopulations. Anal Biochem 368: 193-204.

Ha T (2001) Single-molecule fluorescence resonance energy transfer. Methods 25: 78-86.

Hall MC, Matson SW (1999) Helicase motifs: the engine that powers DNA unwinding. Mol Microbiol 34: 867-877.

Harp JM, Hanson BL, Timm DE, Bunick GJ (2000) Asymmetries in the nucleosome core particle at $2.5 \AA$ resolution. Acta Crystallogr D Biol Crystallogr 56: 1513-1534.

Hegner M, Smith SB, Bustamante C (1999) Polymerization and mechanical properties of single RecA-DNA filaments. Proc Natl Acad Sci U S A 96: 10109-10114.

Hoch DA, Stratton JJ, Gloss LM (2007) Protein-protein Forster resonance energy transfer analysis of nucleosome core particles containing H2A and H2A.Z. J Mol Biol 371: 971-988. 
Iordanescu S (1993) Characterization of the Staphylococcus aureus chromosomal gene pcrA, identified by mutations affecting plasmid pT181 replication. Mol Gen Genet 241: 185-192.

Ishimi Y, Yasuda H, Hirosumi J, Hanaoka F, Yamada M (1983) A protein which facilitates assembly of nucleosome-like structures in vitro in mammalian cells. J Biochem (Tokyo) 94: 735-744.

JBC (1999) Minireview series on single-molecules edited by K. van Holde. J Biol Chem 274.

Ji Y, Zhang B, Van SF et al. (2001) Identification of critical staphylococcal genes using conditional phenotypes generated by antisense RNA. Science 293: 2266-2269.

Joo C, McKinney SA, Nakamura M, Rasnik I, Myong S, Ha T (2006) Real-time observation of RecA filament dynamics with single monomer resolution. Cell 126: 515-527.

Kang J, Blaser MJ (2006) UvrD helicase suppresses recombination and DNA damage-induced deletions. $J$ Bacteriol 188: 5450-5459.

Kelbauskas L, Chan N, Bash R et al. (2008) Sequence-dependent variations associated with $\mathrm{H} 2 \mathrm{~A} / \mathrm{H} 2 \mathrm{~B}$ depletion of nucleosomes. Biophys J. 94: 147-158.

Kelbauskas L, Chan N, Bash R, Yodh J, Woodbury N, Lohr D (2007) Sequence-dependent nucleosome structure and stability variations detected by Forster resonance energy transfer. Biochemistry 46: 2239-2248.

Kelley De Zutter J, Forget AL, Logan KM, Knight KL (2001) Phe217 regulates the transfer of allosteric information across the subunit interface of the RecA protein filament. Structure 9: $47-55$.

Koopmans WJ, Brehm A, Logie C, Schmidt T, van Noort J (2007) Single-pair FRET microscopy reveals mononucleosome dynamics. J Fluoresc 17: 785-795.

Korolev S, Hsieh J, Gauss GH, Lohman TM, Waksman G (1997) Major domain swiveling revealed by the crystal structures of complexes of $E$. coli Rep helicase bound to single-stranded DNA and ADP. Cell 90: 635-647.

Kowalczykowski SC (1991) Biochemistry of genetic recombination: energetics and mechanism of DNA strand exchange. Annu Rev Biophys Biophys Chem 20: 539-575.

Krejci L, Van Komen S, Li Y et al. (2003) DNA helicase Srs2 disrupts the Rad51 presynaptic filament. Nature 423: 305-309.

Krishna R, Manjunath GP, Kumar P et al. (2006) Crystallographic identification of an ordered C-terminal domain and a second nucleotide-binding site in RecA: new insights into allostery. Nucleic Acids Res 34: 2186-2195.

Lane HE, Denhardt DT (1975) The rep mutation. IV. Slower movement of replication forks in Escherichia coli rep strains. $J$ Mol Biol 97: 99-112.

Lee JY, Yang W (2006) UvrD helicase unwinds DNA one base pair at a time by a two-part power stroke. Cell 127: 1349-1360.

Leger JF, Robert J, Bourdieu L, Chatenay D, Marko JF (1998) RecA binding to a single double-stranded DNA molecule: a possible role of DNA conformational fluctuations. Proc Natl Acad Sci U S A 95: 12295-12299.

Leuba SH, Zlatanova J, eds. (2001) Biology at the Single-Molecule Level. Amsterdam: Pergamon.

Leuba SH, Zlatanova J (2002) Single-molecule studies of chromatin fibers: a personal report. Arch Histol Cytol 65: 391-403.
Leuba SH, Bennink ML, Zlatanova J (2004) Single-molecule analysis of chromatin. Methods Enzymol 376: 73-105.

Li BS, Sattin BD, Goh MC (2006) Direct and real-time visualization of the disassembly of a single RecA-DNAATPgammaS complex using AFM imaging in fluid. Nano Lett 6: $1474-1478$.

Li G, Widom J (2004) Nucleosomes facilitate their own invasion. Nat Struct Mol Biol 11: 763-769.

Li G, Levitus M, Bustamante C, Widom J (2005) Rapid spontaneous accessibility of nucleosomal DNA. Nat Struct Mol Biol 12: 46-53.

Lindsley JE, Cox MM (1990) Assembly and disassembly of RecA protein filaments occur at opposite filament ends. Relationship to DNA strand exchange. J Biol Chem 265: 9043-9054.

Lohman TM (1993) Helicase-catalyzed DNA unwinding. $J$ Biol Chem 268: 2269-2272.

Lovullo D, Daniel D, Yodh J, Lohr D, Woodbury NW (2005) A fluorescence resonance energy transfer-based probe to monitor nucleosome structure. Anal Biochem 341: 165-172.

Luger K, Mäder AW, Richmond RK, Sargent DF, Richmond TJ (1997) Crystal structure of the nucleosome core particle at $2.8 \AA$ resolution. Nature 389: 251-260.

Marky NL, Manning GS (1991) The elastic resilience of DNA can induce all-or-none structural transitions in the nucleosome core particle. Biopolymers 31: 1543-1557.

Marky NL, Manning GS (1995) A theory of DNA dissociation from the nucleosome. J Mol Biol 254: 50-61.

McGrew DA, Knight KL (2003) Molecular design and functional organization of the RecA protein. Crit Rev Biochem Mol Biol 38: $385-432$.

McRee DE (1993) Practical Protein Crystallography. San Diego: Academic Press.

Morimatsu K, Kowalczykowski SC (2003) RecFOR proteins load RecA protein onto gapped DNA to accelerate DNA strand exchange: a universal step of recombinational repair. Mol Cell 11: $1337-1347$.

Mujumdar RB, Ernst LA, Mujumdar SR, Lewis CJ, Waggoner AS (1993) Cyanine dye labeling reagents: sulfoindocyanine succinimidyl esters. Bioconjug Chem 4: 105-111.

Myong S, Rasnik I, Joo C, Lohman TM, Ha T (2005) Repetitive shuttling of a motor protein on DNA. Nature 437: 1321-1325.

Myung K, Datta A, Chen C, Kolodner RD (2001) SGS1, the Saccharomyces cerevisiae homologue of BLM and WRN, suppresses genome instability and homeologous recombination. Nat Genet 27: 113-116.

Naqvi A, Tinsley E, Khan SA (2003) Purification and characterization of the PcrA helicase of Bacillus anthracis. J Bacteriol 185: 6633-6639.

Park YJ, Dyer PN, Tremethick DJ, Luger K (2004) A new fluorescence resonance energy transfer approach demonstrates that the histone variant $\mathrm{H} 2 \mathrm{AZ}$ stabilizes the histone octamer within the nucleosome. J Biol Chem 279: 24274-24282.

Petit MA, Ehrlich D (2002) Essential bacterial helicases that counteract the toxicity of recombination proteins. EMBO J 21: 3137-3147.

Petit MA, Dervyn E, Rose M et al. (1998) PcrA is an essential DNA helicase of Bacillus subtilis fulfilling functions both in repair and rolling-circle replication. Mol Microbiol 29: 261-273. 
Rajan R, Bell CE (2004) Crystal structure of RecA from Deinococcus radiodurans: insights into the structural basis of extreme radioresistance. J Mol Biol 344: 951-963.

Register JC 3rd, Griffith J (1985) The direction of RecA protein assembly onto single strand DNA is the same as the direction of strand assimilation during strand exchange. J Biol Chem 260: 12308-12312.

Rigler R, Basche T, Orrit M, eds. (2002) Single Molecule Spectroscopy. Nobel conference lectures. Berlin: Springer Verlag.

Roca AI, Cox MM (1997) RecA protein: structure, function, and role in recombinational DNA repair. Prog Nucleic Acid Res Mol Biol 56: 129-223.

Ruiz-Maso JA, Anand SP, Espinosa M, Khan SA, del Solar G (2006) Genetic and biochemical characterization of the Streptococcus pneumoniae PcrA helicase and its role in plasmid rolling circle replication. J Bacteriol 188: 7416-7425.

Science (1999) March issue devoted to reviews on single-molecule approaches. Science $\mathbf{2 8 3}$.

Scott JF, Eisenberg S, Bertsch LL, Kornberg A (1977) A mechanism of duplex DNA replication revealed by enzymatic studies of phage phi X174: catalytic strand separation in advance of replication. Proc Natl Acad Sci U S A 74: 193-197.

Selvin PR (2000) The renaissance of fluorescence resonance energy transfer. Nat Struct Biol 7: 730-734.

Shan Q, Bork JM, Webb BL, Inman RB, Cox MM (1997) RecA protein filaments: end-dependent dissociation from ssDNA and stabilization by $\mathrm{RecO}$ and $\mathrm{RecR}$ proteins. J Mol Biol 265: 519-540.

Shivashankar GV, Feingold M, Krichevsky O, Libchaber A (1999) RecA polymerization on double-stranded DNA by using singlemolecule manipulation: the role of ATP hydrolysis. Proc Natl Acad Sci U S A 96: 7916-7921.

Stasiak A, Di Capua E, Koller T (1981) Elongation of duplex DNA by recA protein. $J$ Mol Biol 151: 557-564.

Story RM, Weber IT, Steitz TA (1992) The structure of the E. coli recA protein monomer and polymer. Nature 355: 318-325.

Subramanya HS, Bird LE, Brannigan JA, Wigley DB (1996) Crystal structure of a DExx box DNA helicase. Nature 384: 379-383.

Tan E, Wilson TJ, Nahas MK, Clegg RM, Lilley DM, Ha T (2003) A four-way junction accelerates hairpin ribozyme folding via a discrete intermediate. Proc Natl Acad Sci U S A 100: 9308-9313.

Tatchell K, Van Holde KE (1977) Reconstitution of chromatin core particles. Biochemistry 16: 5295-5303.

Taucher-Scholtz G, Abdel-Monem M, Hoffman-Berling H (1983) Functions of DNA helicases in Escherichia coli. In: Cozzarelli NR, ed. Mechanism of DNA Replication and Recombination. New York: A. R. Liss, pp. 65-76.

Tomschik M, Zheng H, van Holde K, Zlatanova J, Leuba SH (2005) Fast, long-range, reversible conformational fluctuations in nucleosomes revealed by single-pair fluorescence resonance energy transfer. Proc Natl Acad Sci U S A 102: 3278-3283.

Tóth K, Brun N, Langowski J (2001) Trajectory of nucleosomal linker DNA studied by fluorescence resonance energy transfer. Biochemistry 40: 6921-6928.

Tóth K, Brun N, Langowski J (2006) Chromatin compaction at the mononucleosome level. Biochemistry 45: 1591-1598.
Travers AA, Owen-Hughes T (2004) Nucleosome remodeling. In: Zlatanova J, Leuba SH, eds. Chromatin Structure and Dynamics: State-of-the-Art. Amsterdam: Elsevier. 39: 421-465.

Traverso G, Bettegowda C, Kraus J et al. (2003) Hyperrecombination and genetic instability in BLM-deficient epithelial cells. Cancer Res 63: 8578-8581.

van Holde KE (1988) Chromatin. New York: Springer-Verlag.

van Holde K, Zlatanova J (2006) Scanning chromatin: a new paradigm? J Biol Chem 281: 12197-12200.

Veaute X, Jeusset J, Soustelle C, Kowalczykowski SC, Le Cam E, Fabre F (2003) The Srs2 helicase prevents recombination by disrupting Rad51 nucleoprotein filaments. Nature 423: 309-312.

Veaute X, Delmas S, Selva M et al. (2005) UvrD helicase, unlike Rep helicase, dismantles RecA nucleoprotein filaments in Escherichia coli. EMBO J 24: 180-189.

Velankar SS, Soultanas P, Dillingham MS, Subramanya HS, Wigley DB (1999) Crystal structures of complexes of PcrA DNA helicase with a DNA substrate indicate an inchworm mechanism. Cell 97: 75-84.

Watt PM, Louis EJ, Borts RH, Hickson ID (1995) Sgs1: a eukaryotic homolog of E. coli RecQ that interacts with topoisomerase II in vivo and is required for faithful chromosome segregation. Cell 81: 253-260.

Weiss S (1999) Fluorescence spectroscopy of single biomolecules. Science 283: 1676-1683.

White CL, Luger K (2004) Defined structural changes occur in a nucleosome upon Amt 1 transcription factor binding. $J$ Mol Biol 342: 1391-1402.

Wolffe AP (1998) Chromatin: Structure and Function. New York: Academic Press.

Yang JG, Madrid TS, Sevastopoulos E, Narlikar GJ (2006) The chromatin-remodeling enzyme ACF is an ATP-dependent DNA length sensor that regulates nucleosome spacing. Nat Struct Mol Biol 13: 1078-1083.

Zander C, Enderlein J, Keller RA, eds. (2002) Single Molecule Detection in Solution. Berlin: Wiley-VCH.

Zheng H, Tomschik M, Zlatanova J, Leuba SH (2005) Evanescent field fluorescence microscopy for analysis of protein/DNA interactions at the single-molecule level. In: Golemis E, Adams P, eds. Protein Protein Interactions, A Molecular Cloning Manual. Cold Spring Harbor, NY: Cold Spring Harbor Laboratory Press, pp. 429-444.

Zheng H, Goldner LS, Leuba SH (2007) Homebuilt singlemolecule scanning confocal fluorescence microscope studies of single DNA-protein interactions. Methods 41: 342-352.

Zivanovic Y, Duband-Goulet I, Schultz P, Stofer E, Oudet P, Prunell A (1990) Chromatin reconstitution on small DNA rings. III. Histone H5 dependence of DNA supercoiling in the nucleosome. J Mol Biol 214: 479-495.

Zlatanova J (2003) Forcing chromatin. J Biol Chem 278: 2321323216.

Zlatanova J, Leuba SH (2002) Stretching and imaging single DNA molecules and chromatin. J Muscle Res Cell Motil 23: 377-395.

Zlatanova J, Leuba SH (2003a) Magnetic tweezers: a sensitive tool to study DNA and chromatin at the single-molecule level. Biochem Cell Biol 81: 151-159. 
Zlatanova J, Leuba SH (2003b) Chromatin fibers, one-at-a-time. J Mol Biol 331: 1-19.

Zlatanova J, Leuba SH, eds (2004a) Chromatin Structure and Dynamics: State-of-the-Art. New Comprehensive Biochemistry. Amsterdam: Elsevier.

Zlatanova J, Leuba SH (2004b) Chromatin structure and dynamics: lessons from single molecule approaches. Chromatin Structure and Dynamics: State-of-the-Art. Zlatanova J, Leuba SH, eds. Amsterdam: Elsevier. 39, pp. 369-396.

Zlatanova J, van Holde K (2006) Single-molecule biology: what is it and how does it work? Mol Cell 24: 317-329.

Zlatanova J, McAllister WT, Borukhov S, Leuba SH (2006) Single-molecule approaches reveal the idiosyncrasies of RNA polymerases. Structure 14: 953-966. 